\title{
Examining the Racial Crossover in Mortality between African American and White Older Adults: A Multilevel Survival Analysis of Race, Individual Socioeconomic Status, and Neighborhood Socioeconomic Context
}

\author{
Li Yao ${ }^{1}$ and Stephanie A. Robert ${ }^{2}$ \\ ${ }^{1}$ Department of Human Development and Family Studies, University of Wisconsin-Madison, 1430 Linden Drive, \\ Madison, WI 53706-1575, USA \\ ${ }^{2}$ School of Social Work, University of Wisconsin-Madison, 1350 University Avenue, Madison, WI 53706, USA
}

Correspondence should be addressed to Stephanie A. Robert, sarobert@wisc.edu

Received 20 February 2011; Accepted 10 May 2011

Academic Editor: Bo A. Hagberg

Copyright ( $) 2011$ L. Yao and S. A. Robert. This is an open access article distributed under the Creative Commons Attribution License, which permits unrestricted use, distribution, and reproduction in any medium, provided the original work is properly cited.

\begin{abstract}
We examine whether individual and neighborhood socioeconomic context contributes to black/white disparities in mortality among USA older adults. Using national longitudinal data from the Americans' Changing Lives study, along with census tract information for each respondent, we conduct multilevel survival analyses. Results show that black older adults are disadvantaged in mortality in younger old age, but older black adults have lower mortality risk than whites after about age 80 . Both individual SES and neighborhood socioeconomic disadvantage contribute to the mortality risk of older adults but do not completely explain race differences in mortality. The racial mortality crossover persists even after controlling for multilevel SES, suggesting that black older adults experience selective survival at very old ages. Addressing the individual and neighborhood socioeconomic disadvantage of blacks is necessary to reduce mortality disparities that culminate in older adulthood.
\end{abstract}

\section{Introduction}

Black older adults (ages $65+$ ) have higher all-cause mortality rates than white older adults in the USA $[1,2]$. A growing body of literature attempts to understand the mechanisms explaining these persisting race differences in mortality [3-5] so that we can understand how such race disparities might be reduced or eliminated. Substantial disparities in individual socioeconomic status (SES) by race have been observed in the USA, and research has shown that individual SES (e.g., income and education) partly mediates but does not eliminate the relationship between race and mortality [6-8]. In addition, neighborhood context has been identified as a key factor that contributes to race disparities in morbidity [911]. However, few studies have examined how neighborhood context contributes to race difference in mortality $[12,13]$, particularly at older ages.
The current study employees mixed effect survival analysis to investigate whether SES, measured at both the individual and neighborhood levels, explains black/white differences in mortality among older adults in the USA, using longitudinal national data.

A number of theoretical perspectives, including economic deprivation [14] and social disorganization theory $[15,16]$, suggest that neighborhood context is associated with health and mortality. Some studies have shown that living in a poor neighborhood is related to increased causespecific mortality among adults [17-20], after controlling for individual SES variables. However, other studies have shown that there is no significant association between neighborhood context and all-cause mortality for older adults $[11,21,22]$.

Very few studies have examined the contribution of neighborhood socioeconomic context to race disparities 
in mortality for older adults, although some research has examined this question for younger and middle-aged adults. LeClere and colleagues found that the differential all-cause mortality rates between African American and non-Hispanic white men and women aged 18 and older were partly explained by individual-level SES and were further explained by neighborhood context. The differences in mortality between the black and white adults were completely explained by both individual SES and neighborhood combined [23]. However, some studies indicate that race differences in mortality persist among USA adults even after both individual SES and neighborhood context are controlled. For example, one study demonstrated that mortality for all racial/ethnic groups is related to individual SES and to neighborhood characteristics, among people aged 18-64. The race difference in mortality persisted after controlling for both individual and neighborhood level SES [24].

With regard to older adults, LeClere and colleagues showed that the percentage of female-headed families in the neighborhood was associated with heart disease mortality for women aged 65 and above. Individual SES and neighborhood context fully accounted for the heart disease mortality disparity between white and black older adults [12]. The above research provides some knowledge about the relationships among race, multilevel SES, and all-cause mortality, but the results are not consistent.

Moreover, this body of research has not fully considered the shape of the relationship between race and mortality at older ages. However, research suggests that there is a racial mortality crossover at older ages such that black older adults have higher mortality than white older adults in young older ages while white older adults have higher mortality than their black counterparts in very late old age [25-30]. It could be that the racial mortality crossover in late old age contributes to the inconsistent conclusions regarding the role of multilevel SES in explaining race difference in mortality among older adults. This is because if crossover effects exist, the effect of race on mortality for a younger subgroup will be positive while the effect of race will be negative for an older age subgroup. Combining age groups together in one "old age" group ages $65+$ may result in the positive and negative effects canceling each other out.

There are two primary competing explanations for racial mortality crossover effects [27]. If black older adults are more likely to misreport their age as older than it really is, this would result in more young black older adults being categorized in the oldest old groups. Alternately, black older adults may experience selective mortality. Since black adults are more likely to die at younger ages, the black survivors at very older age should be very robust. Unfortunately, it is difficult to detect age reporting errors in survey data. In any case, the potential existence of the racial mortality crossover effect means that, when studying race differences in mortality among older adults, it is necessary to consider the interaction of race and age.

There have been theoretical debates on the expected patterns of race disparities in mortality over the life course. The double jeopardy hypothesis suggests that blacks are faced with a double burden on health with aging and therefore should experience worse health status and mortality compared to whites at older ages [31]. Another perspective hypothesizes persistent inequality - that race differences in health are set at earlier ages and are then relatively stable throughout the aging process [32]. These two perspectives suggest that crossover effects should not exist. A third perspective describes a different story in which some factors that affect health at younger ages are not as strongly associated with changes in health at older ages. In particular, social factors may be less important than biological factors at older ages. For example, the research by House et al. [33] suggests that the relationship between SES, other risk factors, and health may be buffered by biological robustness (in early adulthood), biological frailty (in later old age), or the existence of social welfare programs, particularly at older ages. This third perspective suggests that the race difference will reduce or even crossover at older ages.

Empirical studies provide some support for the third perspective and have shown that the health disadvantage of blacks not only disappears but crosses over such that black older adults have lower mortality ratios at very old ages (around age 80) [27, 34, 35]. If this crossover effect happens, it may obscure the true relationships among race, multilevel SES and mortality among older adults in different age groups. Given this consideration, we examine the potential for a race crossover effect in mortality among older adults and reexamine the contribution of multilevel SES to mortality and its variation by age among older adults.

Our study extends prior work in a number of ways. The existing literature has contrary findings on the effects of neighborhood context on mortality and the magnitude of the effects of neighborhood context on explaining race differences in mortality among older adults. A number of limitations to prior work may cause this contradiction. First, as described above, most studies examine all older adults combined, rather than examining age-specific changes among older adults. Second, most studies examined diseasespecific mortality, but it is also important to understand how multilevel SES is associated with all-cause mortality. Third, most previous studies used a single indicator or separate indicators of neighborhood context, whereas we combine a number of neighborhood variables to create a more comprehensive neighborhood disadvantage index.

Fourth, our statistical approach represents an improvement on prior work in the USA because we use multilevel survival analyses to account for the multilevel nature of the data while modeling mortality using the greater precision of survival analysis. Most prior work in the USA has not adjusted for the complex survey design effects that result from the multistate sampling method of the data or the nested nature of the individual-level data within neighborhoods, leading to potentially incorrect variance and parameter estimates [36-38]. Some studies considered the correlated data structure and used multilevel logistic regression to estimate the association between multilevel SES and mortality $[11,22,39,40]$. But in these studies, censoring issues were not addressed leading to potential errors in estimates. Recently, a few studies employed multilevel survival 
analysis, which combines the advantages of mixed effects model and Cox proportional hazard model to estimate the effects of multilevel SES on cause-specific mortality [17$19,41]$ and all-cause mortality [42]. However, these studies were based in European countries. We utilize this method using a USA sample.

In sum, results regarding the effects of neighborhood SES on mortality and its contribution to race differences in mortality among older adults are mixed. Some national studies provided evidence that multilevel SES is associated with mortality and contributes to explaining race differences in mortality [12, 23, 24, 43]. However, there is still a debate on the magnitude of their contribution to race differences in mortality, particularly at older ages. We build from and attempt to improve upon prior work by introducing an interaction between race and age. We also use multilevel survival models to appropriately estimate the associations between race, the interaction of race and age, individual SES, neighborhood SES, and all-cause mortality over 16 years among older adults in a nationally representative sample of adults in the USA.

\section{Materials and Methods}

2.1. Data. Wave 1 (W1) of the Americans Changing Lives (ACL) study was conducted in 1986 through face-to-face interviews in the homes of 3,617 adults. The sample was created using a multistage, stratified area probability sample of noninstitutionalized adults aged 25 and older living in the 48 contiguous states, with oversamples of black people and older adults. We limit our analysis to the cohort of people ages 65 and older in order to replicate and extend previous studies that looked at this age cohort $[3,25,44,45]$. The analytic sample used in this study includes respondents aged 65 or older at W1 (with survivors being aged 81 or older at wave 4) who reported their race as white or black, for a final analytic sample of 1211 respondents aged 65 and older at W1.

Neighborhood variables are taken from the 1990 census at the census tract level, based on each individual's residence at W1 of the interview.

Data were collected by the University of Michigan using approved human subjects protocols. Data analyses were conducted with approval by the University of WisconsinMadison social studies institutional review board.

2.2. Variables. Education is measured as years of formal schooling completed by $\mathrm{W} 1$ and is included as a continuous variable. Family income at baseline is included as an ordinal variable ranging from 1 to $10(1=$ less than $\$ 5 \mathrm{~K}$; $2=\$ 5 \mathrm{~K}-\$ 9999 ; 3=\$ 10 \mathrm{~K}-14,999 ; 4=\$ 15 \mathrm{~K}-19,999 ;$ $5=\$ 20 \mathrm{~K}-24,999 ; 6=\$ 25 \mathrm{~K}-29,999 ; 7=\$ 30 \mathrm{~K}-39,999 ;$ $8=\$ 40 \mathrm{~K}-59,999 ; 9=\$ 60 \mathrm{~K}-79,999 ; 10=\$ 80 \mathrm{~K}$ and above). Regression-based imputations were made for missing income data.

Five neighborhood characteristics (\% adults aged 25+ with $16+$ years schooling, $\%$ households with public assistance, $\%$ persons aged $65+$ below poverty line, $\%$ families that are female-headed, and mean family income) are used to create a neighborhood socioeconomic disadvantage index (Neighborhood SDI). After conducting a factor analysis (see Table 3), each of the five neighborhood measures was standardized, weighted by its factor loading, and summed (\% adults aged 25+ with $16+$ years schooling and mean family income were reversed) to create the Neighborhood SDI. A higher score means greater neighborhood disadvantage.

Gender is coded 1 for men and 0 for women. Race is a dummy variable $($ Black $=1$; White $=0)$.

The dependent variable at each wave is all-cause mortality. Mortality was tracked over time and was confirmed with the National Death Index (coded to the year of death) through wave 4 (2001) [33].

2.3. Statistical Analysis. Survival analysis is used to examine predictors of time until death. The basic Cox proportional hazards regression is expressed as $[46,47]$

$$
h(t \mid Z)=h_{0}(t) \exp \left(\sum_{k=1}^{p} \beta_{k} Z_{k}\right) .
$$

$h(t \mid Z)$ is the hazard rate at time $t$ for an individual covariates vector $Z$. $h_{0}(t)$ is an arbitrary baseline hazard rate. $\beta_{k}$ is the estimated parameter vector that represents the direction and magnitude of the association between $Z_{k}$ and $h(t \mid Z)$ compared to baseline hazard rate. If we assume that censoring time and event for the $j$ th participants are independent given by $Z_{k}$, the parameters in (1) could be estimated by maximizing the partial likelihood function in

$$
L(\beta)=\prod_{i=1}^{D} \frac{\exp \left[\sum_{k=1}^{p} \beta_{k} Z_{(i) k}\right]}{\sum_{j \in R\left(t_{i}\right)} \exp \left[\sum_{k=1}^{p} \beta_{k} Z_{j k}\right]} .
$$

In (2), let $t_{1}>t_{2} \ldots<\mathrm{T}_{\mathrm{D}}$ denote the ordered event times. $Z_{(i) k}$ is the $k$ th covariate associated with individual whose death time is $t_{i} . R\left(t_{i}\right)$ represents the $k$ th covariate associated with individuals who are still in the risk set at a time just prior to $t_{i}$. The numerator in (2) represents the information about death where the denominator includes all information about individuals who have not yet died.

When neighborhood socioeconomic context is included in analysis, we model the association between individual survival times within neighborhood. There is an unobservable random effect shared by subjects within a neighborhood. In this case, Cox proportional hazard mixed effects model (PHMM) is appropriate [46, 48, 49]. To simplify the model, one time-invariant neighborhood socioeconomic context variable is included in the analysis. The hazard function for the $j$ th individual in $i$ neighborhood can be expressed as $[50,51]$

$$
h_{i j}(t \mid Z)=h_{0}(t) \exp \left(\beta^{\prime} Z_{i j}+b_{i}^{\prime} \omega_{i j}\right) .
$$

$Z_{i j}$ is the vector covariate and $\beta$ is the vector of regression coefficient. $\omega_{i j}$ is a vector of covariates that have random effects. This equation captures the random effects of the cluster and enables covariate by cluster interactions. Due to the interaction of clustered and individual covariates, $\omega_{i j}$ is a subset of $Z_{i j}[51,52]$. 
TABle 1: Descriptive statistics (unweighted): percentage distribution or mean (standard deviation in parentheses) at baseline for independent variables (respondents aged 65 and above at baseline, $N=1211)$.

\begin{tabular}{lcc}
\hline Variables & Range & Percentages or mean \\
\hline Male (\%) & $0-1$ & 31.23 \\
Black (\%) & $0-1$ & 28.98 \\
Age & $65-96$ & $73.13(6.34)$ \\
Income & $1-10$ & $3.18(2.16)$ \\
Education & $0-17$ & $9.99(3.75)$ \\
Neighborhood SDI & $-3.22-3.26$ & $0(1)$ \\
(standardized) & & \\
\hline
\end{tabular}

Neighborhood SDI: Neighborhood Socioeconomic Disadvantage Index.

2.4. Analytic Strategy. A series of Cox proportional hazard models will be presented to examine the association between race, multilevel SES, and mortality. Models 1 to 4 in Table 2 use Cox proportional hazards regression to estimate the contribution of both individual SES and neighborhood SDI to race differences in mortality when neighborhood-level variance is ignored. Mixed effect cox analyses are shown in Models $1 \mathrm{~b}$ to $4 \mathrm{~b}$ in Table 2 in order to examine how multilevel SES explains race disparity in mortality when we consider the neighborhood-level variance. Finally, the interaction between race and age is introduced in Models 5 to 7 to investigate whether race differences in mortality differ by different age groups after multilevel SES is controlled.

\section{Results}

Table 1 presents the descriptive information for the demographic and socioeconomic measures at baseline for 1211 older adults aged 65 and above who reported their race as either white or black. About one third of participants were male, about $45 \%$ were married at baseline, and the average age was 73 . The mean years of education are about 10 . The average family income was in the range of $\$ 15,000$ to $\$ 19,999$ in 1986.

The effects of individual SES and neighborhood SDI on mortality are presented in Table 2 . Model 1 in Table 2 shows that black older adults had a higher mortality rate $\left(e^{* *} 0.167=1.18\right)$ than white older adults. The probability of dying (at an earlier age or by the end of the study period) for black older adults is on average 18\% higher than the probability of death for white older adults. When only individual SES measures were added in Model 2, race differences in mortality disappeared and family income is negatively related to mortality. Model 3 examines the effects of neighborhood SDI on mortality. First, we find that neighborhood SDI is positively associated with mortality. This model suggests that, if the neighborhood socioeconomic disadvantage index increases by one standard deviation, the probability of death increases by $10 \%\left(\mathrm{e}^{* *} 0.091=1.0953\right)$. Race differences in mortality persist after controlling for neighborhood SDI. Both individual SES and neighborhood SES were included simultaneously in Model 4. Model 4 indicates that both family income and neighborhood SDI are significantly related to mortality. However, there is no remaining statistically significant race difference in mortality.

Models $1 \mathrm{~b}-4 \mathrm{~b}$ in Table 2, using mixed effects Cox model, demonstrate similar results. Both individual SES and neighborhood SDI are related to mortality. Race differences in mortality are fully mediated by individual SES. Looking at Models 2-4 and 2b-4b together, we conclude that individual SES is stronger than neighborhood SDI in explaining race differences in mortality.

The interaction of race by age was added in Models 5-7 in Table 2 in order to investigate whether race disparities in mortality vary by age among older adults. Model 5 indicates that there is a significant interaction of race and age, which means that race differences in mortality are not constant across age for older adults. The positive coefficients for race and age and the negative coefficient for the interaction of race and age support theories that suggest a diminishing or crossover effect of race rather than theories suggesting a double jeopardy hypothesis. The positive coefficient of race suggests that black adults experienced a greater risk of death at young old ages. The negative coefficient of the interaction of race and age shows that black older adults' risk of morality increases at a slower rate than white older adults' risk. We compute the turning point age where black and white older adults have an equal risk of mortality after controlling other covariates in Model 5. The formula is $3.028^{*} 1+0.106^{*}$ age $0.038^{*}$ age $=3.028^{*} 0+0106^{*}$ age $-0.038^{*} 0$ and we get age $=$ 79.68. This means that after around age 80 , black older adults had lower risk of dying than whites.

In Model 6, we include individual SES measures to examine their effects on mortality and their contribution to race differences in mortality by age. First, as in Models 14 and Models $1 \mathrm{~b}-4 \mathrm{~b}$, family income is negatively associated with mortality. Second, including individual SES measures reduced but did not fully explain race differences in mortality by age.

Neighborhood SDI is added in Model 7. We see that living in a neighborhood with greater disadvantage is associated with a greater risk of dying $\left(e^{* *} 0.086=1.09\right)$, net of demographic, and individual SES variables, and it further reduces the association between race and mortality by age. Again, there remains a significant racial crossover effect on mortality due to the positive coefficient of race and negative coefficient of the interaction of race and age. The turning point of the crossover is about 74 after controlling for SES at multiple levels.

Finally, all variances of neighborhood tracts are significant in Models $1 \mathrm{~b}$ to $4 \mathrm{~b}$ and Models 5 to 7 . The standard error presents how much an individual neighborhood varies in its mortality rate compared to the norm $[53,54]$. For example, the variance is 0.0051 in Model $4 \mathrm{~b}$. Its standard error is 0.07 . This suggests that an individual neighborhood has an average 7 percent higher or lower mortality level compared to the norm. This relatively large variation between neighborhoods suggests that it is appropriate to model neighborhood-level variance in mortality analyses among older adults. 
TABLE 2: The effect of individual SES, neighborhood context on mortality over time (1986-2002) for people aged 65+ at baseline: multilevel survival model.

\begin{tabular}{|c|c|c|c|c|c|c|c|c|c|c|c|}
\hline Variables & Model & Model 2 & Model 3 & Model 4 & Model 1b & Model 2b & Model 3b & Model 4b & Model 5 & Model 6 & Model 7 \\
\hline Black & $0.167^{*}$ & 0.013 & $0.163^{* *}$ & -0.010 & $0.192^{* *}$ & 0.040 & $0.180^{*}$ & 0.021 & $3.028^{* * *}$ & $2.672^{* *}$ & $2.529^{*}$ \\
\hline Male & $0.621^{* * *}$ & $0.690 * * *$ & $0.586^{* * *}$ & $0.653 * * *$ & $0.623^{* *}$ & $0.668^{* * *}$ & $0.585^{* * *}$ & $0.632^{* * *}$ & $0.609^{* * *}$ & $0.646^{* * *}$ & $0.614^{* * *}$ \\
\hline Age & $0.087^{* * *}$ & $0.081^{* * *}$ & $0.087^{* * *}$ & $0.081^{* * *}$ & $0.091^{* * *}$ & $0.086^{* * *}$ & $0.091^{* * *}$ & $0.086^{* * *}$ & $0.106^{* * *}$ & $0.100^{* * *}$ & $0.099^{* * *}$ \\
\hline Age*Black & & & & & & & & & $-.038^{* * *}$ & $-0.035^{* *}$ & $-0.034^{* *}$ \\
\hline Fam. Income & & $-.092^{* * *}$ & & $-.093^{* * *}$ & & $-.070^{* * *}$ & & $-.071^{* * *}$ & & $-.063^{* * *}$ & $-0.065^{*}$ \\
\hline Education & & -0.008 & & -0.0119 & & -0.012 & & -0.0151 & & $-.011^{* * *}$ & -0.018 \\
\hline SDI & & & $0.091^{*}$ & $0.107^{* *}$ & & & $0.079 *$ & $0.087^{* *}$ & & & $0.086^{* *}$ \\
\hline Random effect & & & & & $.0096^{* * *}$ & $.0069^{* * *}$ & $.0047^{* * *}$ & $.0051^{* * *}$ & $.0051^{* * *}$ & $.0017^{* * *}$ & $.0017^{* * *}$ \\
\hline
\end{tabular}

${ }^{* * *} P<0.001 ;{ }^{* *} P<0.01 ;{ }^{*} P<0.05 ;{ }^{+} P<0.10$.

SDI: Neighborhood Socioeconomic Disadvantage Index; Random effect: random effects of neighborhood; Fam. income: family income.

TABle 3: Principal components factor analysis of Neighborhood Socioeconomic Disadvantage Index.

\begin{tabular}{lc}
\hline Census item & Factor loading \\
\hline \% 25+ adults with 16+ years schooling & -0.73 \\
\% Households with public assistance & 0.86 \\
\% Persons aged 65+ below poverty line & 0.77 \\
\% Families female-headed & 0.81 \\
Mean family income $^{\mathrm{a}}$ & -0.79 \\
\hline
\end{tabular}

${ }^{\mathrm{a}}$ Reverse-coded when added to index.

In additional analyses, we tested whether race differences in mortality vary by other covariates by testing the interactions of race and other covariates (see Table 4). The results show that no other interactions are significant.

\section{Discussion}

We examined the role of individual SES and neighborhood SES in explaining race differences in all-cause mortality over time among black and white older adults. We explicitly tested whether race disparities in mortality vary by age and examined the contribution of individual and neighborhood SES to explaining age variations in these race disparities.

One debate in previous studies is whether there are effects of neighborhood SES on mortality for older adults. Some studies found that neighborhood context has no effects on mortality, while other studies showed that there is an association between neighborhood and mortality [22]. We believe that inconsistencies in prior work may be partly due to the fact that most prior work did not take into account the correlated data structure and censoring issues related to examining mortality data over time. We applied a multilevel survival approach (COX PH model with mixed effects) to estimate the effects of neighborhood on mortality. We found that older adults who lived in more disadvantaged neighborhoods had a higher mortality rate, which is consistent with the studies that used COX PH model with mixed effects in other countries [17-19, 39]. Thus, we have more confidence in concluding that there is a significant relationship between neighborhood SDI and allcause mortality among older adults in the USA.
The second debate is whether individual SES and neighborhood SES help explain race differences in mortality for older adults. Although only very few studies have implicitly examined this issue, the results have been inconsistent. Some studies showed that individual SES fully mediates the relationship between race and mortality, while other studies found that individual SES helped explain the difference with neighborhood context further explaining the difference. However, none of these prior studies considered or modeled the race crossover effect of mortality between black and white older adults.

In this study, we examined the contribution of individual SES and neighborhood SDI to mortality through two sets of analysis-with and without modeling a racial crossover effect. The analysis without modeling a potential crossover effect showed that individual SES fully mediated the relationship between race and mortality. However, the analysis with the interaction term between age and race demonstrated that there is a race crossover effect and further indicated that race differences in mortality persist after both individual SES and neighborhood SDI were controlled. Our analysis suggests that the crossover effect happens around ages 76-80, which is consistent with previous studies [27,34].

There are a number of implications of this study. First, our study suggests that age reporting bias is probably not the main reason for the racial crossover in mortality. This is because, even if more young black older adults were falsely categorized into the oldest old groups, social factors still exert a large effect on race difference in mortality since significant race differences in mortality exist between blacks and whites at early older age. At the oldest ages, the aging process itself, especially biological factors, may have more weight on mortality and health [33]. Given our data and findings, our results are consistent with a selective mortality explanation for the racial crossover in mortality at later old age for black and white older adults. The selective survival of robust black older adults likely explains the racial crossover.

Another important finding is that our analyses reveal that individual SES explains more of the race differences in mortality than does neighborhood SDI. This is consistent with previous studies [13]. However, we must keep in mind that some of the neighborhood effects on mortality may work through their effects on individual-level income 
TABLE 4: The effect of individual SES and neighborhood context on mortality over time (1986-2002) for people aged 65+ at baseline: multilevel survival model (including interactions of race and other covariates).

\begin{tabular}{|c|c|c|c|c|}
\hline Variables & Model 1 & Model 2 & Model 3 & Model 4 \\
\hline Black & 0.102 & 0.013 & 0.222 & 0.222 \\
\hline Male & $0.711^{* * *}$ & $0.632 * * *$ & $0.634^{* * *}$ & $0.632 * * *$ \\
\hline Age & $0.085^{* *}$ & $0.085^{* *}$ & $0.086^{* * *}$ & $0.0852 * * *$ \\
\hline \multicolumn{5}{|l|}{ Black*age } \\
\hline Black*male & -0.254 & & & \\
\hline Black*F-income & & 0.0040 & & \\
\hline Black* education & & & 0.0283 & \\
\hline Black*Neigh. SDI & & & & 0.0086 \\
\hline F-income & $-0.071^{*}$ & $-0.071^{*}$ & $-0.066^{*}$ & $-0.070^{* *}$ \\
\hline Education & -0.015 & -0.015 & -0.026 & -0.014 \\
\hline Neighborhood SDI & $0.075+$ & $0.075+$ & $0.079^{*}$ & 0.077 \\
\hline Random effect & 0.0052 & 0.0051 & 0.0051 & 0.0051 \\
\hline
\end{tabular}

${ }^{* * *} P<0.001 ;{ }^{* *} P<0.01 ;{ }^{*} P<0.05 ;{ }^{+} P<.10$.

Neighborhood SDI: Neighborhood Socioeconomic Disadvantage Index; Random effect: random effects of neighborhood; F-income: Family income.

over the life course. Actual neighborhood effects are likely understated when individual-level income is controlled.

There are a number of limitations to our study. First, we only include white and black older adults in our analysis due to sample limitations of racial/ethnic distribution in the ACL data. Future studies should examine how individual and neighborhood socioeconomic context contribute to racial/ethnic disparities in mortality between other racial/ethnic groups. Second, we only include baseline individual SES and neighborhood SDI variables in the analysis. Using these static measures may underestimate their effects on mortality and in explaining race disparities in mortality [55]. Examining how dynamic individual SES and neighborhood SDI measures affect mortality over time for older adults is an interesting and challenging research direction for the future.

Third, we limited our analysis to the cohort of older adults aged 65 and above. It may be interesting to compare the results with other age cutoffs and cohorts. Cohort is an important concept in life course theory [56], which expects that people born at a particular time (cohort effect) may experience similar life events that will affect their life path, SES, health, and mortality [57]. For example, the type and degree of racial discrimination experienced may differ by cohort, affecting race differences in the accumulation of individual-level SES and neighborhood segregation. Testing cohort differences in future research could enrich theory and evidence about how multilevel SES contributes to race difference in mortality.

\section{Conclusion}

Our study extends previous research and contributes to the literature in two major ways. First, we use appropriate statistical methods to estimate the association between multilevel socioeconomic status (at individual and neighborhood levels) and mortality and confirm that older adults living in a disadvantaged neighborhood context experience higher risk of dying at earlier old ages, beyond the impact of individual SES. Second, we demonstrate that there are race crossover effects in mortality at later old age, with black older adults having a mortality advantage at later old age. Moreover, neighborhood SDI helps explain race differences in mortality at older ages. Finally, race differences in mortality did not disappear even after controlling for both individual SES and neighborhood SDI measures once we modeled the racial crossover effect on mortality.

These results help resolve debates in previous studies and help us better understand the association among race, individual SES, and neighborhood context. The socioeconomic contexts that affect black and white Americans into old age affect their mortality risk, leading to selective survival among the most robust black older adults at later old ages. Addressing the individual and neighborhood socioeconomic disadvantage of black people over the life course is necessary to reduce mortality disparities that culminate in early older adulthood.

\section{Acknowledgments}

An earlier version of this paper was presented at the 58th Annual Meeting of the Society for the Study of Social Problems, August, 2009, San Francisco, Calif, USA. Contextual data linkage was supported by NIA Grant R01 AG018418, and the research was primarily supported by NIA Grant R01 AG20247 (Dr. S. A. Robert, Principle Investigator).

\section{References}

[1] R. A. Hummer, M. R. Benjamins, and R. G. Rogers, "Racial and ethnic disparities in health and mortality amony the U.S. elderly population," in Critical Perspectives on Racial and Ethnic Differences in Health in Late Life, N. B. Anderson, R. A. Bulatao, B. Cohen, and National Research Council (U.S.), Eds., pp. 53-94, National Academies Press, Washington, D.C, USA, 2004. 
[2] D. R. Williams and P. B. Jackson, "Social sources of racial disparities in health," Health Affairs, vol. 24, no. 2, pp. 325334, 2005.

[3] L. Berkman, B. Singer, and K. Manton, "Black/white differences in health status and mortality among the elderly," Demography, vol. 26, no. 4, pp. 661-678, 1989.

[4] R. A. Hummer, "Black-white differences in health and mortality: a review and conceptual model," Sociological Quarterly, vol. 37, no. 1, pp. 105-125, 1996.

[5] J. J. Sudano and D. W. Baker, "Explaining US racial/ethnic disparities in health declines and mortality in late middle age: the roles of socioeconomic status, health behaviors, and health insurance," Social Science and Medicine, vol. 62, no. 4, pp. 909 922, 2006.

[6] X. L. Du, S. Fang, S. W. Vernon et al., "Racial disparities and socioeconomic status in association with survival in a large population-based cohort of elderly patients with colon cancer," Cancer, vol. 110, no. 3, pp. 660-669, 2007.

[7] L. Franzini, A. Williams, J. Franklin, S. Singletary, and R. Theriault, "Effects of race and socioeconomic status on survival of 1,332 black, hispanic, and white women with breast cancer," Annals of Surgical Oncology, vol. 4, no. 2, pp. 111-118, 1997.

[8] P. Sorlie, E. Rogot, R. Anderson, N. J. Johnson, and E. Backlund, "Black-white mortality differences by family income," The Lancet, vol. 340, no. 8815, pp. 346-350, 1992.

[9] K. A. Cagney, C. R. Browning, and M. Wen, "Racial disparities in self-rated health at older ages: what difference does the neighborhood make?" The Journals of Gerontology, vol. 60, no. 4, pp. S181-S190, 2005.

[10] S. A. Robert and E. Ruel, "Racial segregation and health disparities between black and white older adults," The Journals of Gerontology, vol. 61, no. 4, pp. S203-S211, 2006.

[11] Y. Li and S. A. Robert, "The contributions of race, individual socioeconomic status, and neighborhood socioeconomic context on the self-rated health trajectories and mortality of older adults," Research on Aging, vol. 30, no. 2, pp. 251-273, 2008.

[12] F. B. LeClere, R. G. Rogers, and K. Peters, "Neighborhood Social Context and Racial Differences in Women's Heart Disease Mortality," Journal of Health and Social Behavior, vol. 39, no. 2, pp. 91-107, 1998.

[13] M. A. Winkleby and C. Cubbin, "Influence of individual and neighbourhood socioeconomic status on mortality among black, Mexican-American, and white women and men in the United States," Journal of Epidemiology and Community Health, vol. 57, no. 6, pp. 444-452, 2003.

[14] A. T. Geronimus, "To mitigate, resist, or undo: addressing structural influences on the health of urban populations," American Journal of Public Health, vol. 90, no. 6, pp. 867-872, 2000.

[15] R. J. Sampson, S. W. Raudenbush, and F. Earls, "Neighborhoods and violent crime: a multilevel study of collective efficacy," Science, vol. 277, no. 5328, pp. 918-924, 1997.

[16] R. J. Sampson, J. D. Morenoff, and T. Gannon-Rowley, "Assessing neighborhood effects: social processes and new directions in research," Annual Review of Sociology, vol. 28, pp. 443-478, 2002.

[17] B. Chaix, L. Maria, L. John, and M. Juan, "Disentangling contextual effects on cause-specific mortality in a longitudinal 23-year follow-up study: impact of population density or socioeconomic environment?" International Journal of Epidemiology, vol. 35, no. 3, pp. 633-643, 2006.

[18] B. Chaix, M. Rosvall, and J. Merlo, "Assessment of the magnitude of geographical variations and socioeconomic contextual effects on ischaemic heart disease mortality: a multilevel survival analysis of a large Swedish cohort," Journal of Epidemiology and Community Health, vol. 61, no. 4, pp. 349355, 2007.

[19] B. Chaix, M. Rosvall, and J. Merlo, "Recent increase of neighborhood socioeconomic effects on ischemic heart disease mortality: a multilevel survival analysis of two large Swedish cohorts," American Journal of Epidemiology, vol. 165, no. 1, pp. 22-26, 2007.

[20] M. Wen and N. A. Christakis, "Neighborhood effects on posthospitalization mortality: a population-based cohort study of the elderly in Chicago," Health Services Research, vol. 40, no. 4, pp. 1108-1127, 2005.

[21] R. T. Anderson, P. Sorlie, E. Backlund, N. Johnson, and G. A. Kaplan, "Mortality effects of community socioeconomic status," Epidemiology, vol. 8, no. 1, pp. 42-47, 1997.

[22] R. G. Wight, J. R. Cummings, A. S. Karlamangla, and C. S. Aneshensel, "Urban neighborhood context and mortality in late life," Journal of Aging and Health, vol. 22, no. 2, pp. 197218, 2010.

[23] F. B. LeClere, R. G. Rogers, and K. D. Peters, "Ethnicity and Mortality in the United States: individual and Community Correlates," Social Forces, vol. 76, no. 1, pp. 169-198, 1997.

[24] S. A. Bond Huie, R. A. Hummer, and R. G. Rogers, "Individual and contextual risks of death among race and ethnic groups in the United States," Journal of Health and Social Behavior, vol. 43, no. 3, pp. 359-381, 2002.

[25] M. C. Corti, J. M. Guralnik, L. Ferrucci et al., "Evidence for a Black-White crossover in all-cause and coronary heart disease mortality in an older population: the North Carolina EPESE," American Journal of Public Health, vol. 89, no. 3, pp. 308-314, 1999.

[26] N. E. Johnson, "The racial crossover in comorbidity, disability, and mortality," Demography, vol. 37, no. 3, pp. 267-283, 2000.

[27] S. M. Lynch, J. S. Brown, and K. G. Harmsen, "Black-white differences in mortality compression and deceleration and the mortality crossover reconsidered," Research on Aging, vol. 25, no. 5, pp. 456-483, 2003.

[28] E. J. Nan, "The racial crossover in comorbidity, disability, and mortality," Demography, vol. 37, no. 3, pp. 267-283, 2000.

[29] K. G. Manton, S. S. Poss, and S. Wing, "The black/white mortality crossover: investigation from the perspective of the components of aging," The Gerontologist, vol. 19, no. 3, pp. 291-300, 1979.

[30] S. Wing, K. G. Manton, E. Stallard, C. G. Hames, and H. A. Tryoler, "The black/white mortality crossover: investigation in a community-based study," The Journals of Gerontology, vol. 40, no. 1, pp. 78-84, 1985.

[31] A. M. O'Rand and J. Hamil-Luker, "Processes of cumulative adversity: childhood disadvantage and increased risk of heart attack across the life course," The Journals of Gerontology, vol. 60, pp. 117-124, 2005.

[32] K. F. Ferraro and M. M. Farmer, "Double jeopardy to health hypothesis for african Americans: analysis and critique," Journal of Health and Social Behavior, vol. 37, no. 1, pp. 2743, 1996.

[33] J. S. House, P. M. Lantz, and P. Herd, "Continuity and change in the social stratification of aging and health over the life course: evidence from a nationally representative longitudinal study from 1986 to 2001/2002 (Americans' Changing Lives Study)," The Journals of Gerontology, vol. 60, pp. 15-26, 2005.

[34] M. C. Corti, J. M. Guralnik, L. Ferrucci et al., "Evidence for a black-white crossover in all-cause and coronary heart disease mortality in an older population: the North Carolina EPESE," 
American Journal of Public Health, vol. 89, no. 3, pp. 308-314, 1999.

[35] I. T. Elo and S. H. Preston, "Racial and ethinic differences in mortality at older ages," in Racial and Ethnic Differences in the Health of Oder Americans, L. G. Martin and B. J. Soldo, Eds., pp. 10-40, National Academies Press, Washington, D.C, USA, 2004.

[36] L. Xiang, K. K. W. Yau, S. K. Tse, and A. H. Lee, "Influence diagnostics for random effect survival models: application to a recurrent infection study for kidney patients on portable dialysis," Computational Statistics \& Data Analysis, vol. 51, no. 12, pp. 5977-5993, 2007.

[37] D. A. Freedman, "On the so-called "Huber Sandwich Estimator" and "robust standard errors"', American Statistician, vol. 60, no. 4, pp. 299-302, 2006.

[38] P. J. Kelly, "A review of software packages for analyzing correlated survival data," American Statistician, vol. 58, no. 4, pp. 337-342, 2004.

[39] H. Bosma, H. Dike van de Mheen, G. J. J. M. Borsboom, and J. P. Mackenbach, "Neighborhood socioeconomic status and allcause mortality," American Journal of Epidemiology, vol. 153, no. 4, pp. 363-371, 2001.

[40] L. L. Roos, J. Magoon, S. Gupta, D. Chateau, and P. J. Veugelers, "Socioeconomic determinants of mortality in two Canadian provinces: multilevel modelling and neighborhood context," Social Science \& Medicine, vol. 59, no. 7, pp. 14351447, 2004.

[41] O. Dejardin, L. Remontet, A. M. Bouvier et al., "Socioeconomic and geographic determinants of survival of patients with digestive cancer in France," British Journal of Cancer, vol. 95, no. 7, pp. 944-949, 2006.

[42] C. Marinacci, T. Spadea, A. Biggeri, M. Demaria, A. Caiazzo, and G. Costa, "The role of individual and contextual socioeconomic circumstances on mortality: analysis of time variations in a city of north west Italy," Journal of Epidemiology and Community Health, vol. 58, no. 3, pp. 199-207, 2004.

[43] P. M. Krueger, S. A. Bond Huie, R. G. Rogers, and R. A. Hummer, "Neighbourhoods and homicide mortality: an analysis of race/ethnic differences," Journal of Epidemiology and Community Health, vol. 58, no. 3, pp. 223-230, 2004.

[44] M. E. Dupre, A. T. Franzese, and E. A. Parrado, "Religious attendance and mortality: implications for the black-white mortality crossover," Demography, vol. 43, no. 1, pp. 141-164, 2006.

[45] S. H. Preston, I. T. Elo, I. Rosenwaike, and M. Hill, "AfricanAmerican mortality at older ages: results of a matching study," Demography, vol. 33, no. 2, pp. 193-209, 1996.

[46] J. P. Klein and M. L. Moeschberger, Survival Analysis: Techniques for Censored and Truncated Data, Springer, New York, NY, USA, 2nd edition, 2003.

[47] P. D. Allison, Survival Analysis Using the SAS System: A Practical Guide, SAS Institute, Cary, NC, USA, 1995.

[48] V. S. Pankratz, M. de Andrade, and T. M. Therneau, "Randomeffects cox proportional hazards model: general variance components methods for time-to-event data," Genetic Epidemiology, vol. 28, no. 2, pp. 97-109, 2005.

[49] V. S. Pankratz, M. De Andrade, and T. M. Therneau, "Random-effects cox proportional hazards model: general variance components methods for time-to-event data," Genetic Epidemiology, vol. 28, no. 2, pp. 97-109, 2005.

[50] F. X. Florin Vaida, "Proportional hazards model with random effects," Statistics in Medicine, vol. 19, no. 24, pp. 3309-3324, 2000.
[51] R. H. Xu, "Proportional hazards mixed models: a review with applications to twin models," Methodoloski Zvezki, vol. 1, pp. 205-212, 2004.

[52] S. Rabe-Hesketh, S. Yang, and A. Pickles, "Multilevel models for censored and latent responses," Statistical Methods in Medical Research, vol. 10, no. 6, pp. 409-427, 2001.

[53] T. M. Therneau and P. M. Grambsch, Penalized Cox Modles and Frailty, 1998.

[54] T. M. Therneau and P. M. Grambsch, Modeling Survival Data: Extending the Cox Model, Springer, New York, NY, USA, 2000.

[55] P. McDonough and P. Berglund, "Histories of poverty and self-rated health trajectories," Journal of Health and Social Behavior, vol. 44, no. 2, pp. 198-214, 2003.

[56] G. H. Elder, M. K. Johnson, and R. Crosnoe, "The emergence and development of the life course theory," in Handbook of the Life Course, J. T. Mortimer and M. J. Shanahan, Eds., Plenum, New York, NY, USA, 2003.

[57] T. R. Holford, "Understanding the effects of age, period, and cohort on incidence and mortality rates," Annual Review of Public Health, vol. 12, pp. 425-457, 1991. 


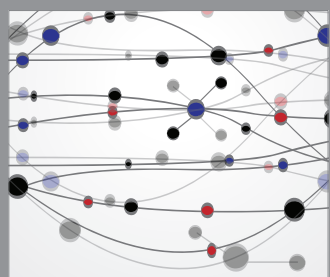

The Scientific World Journal
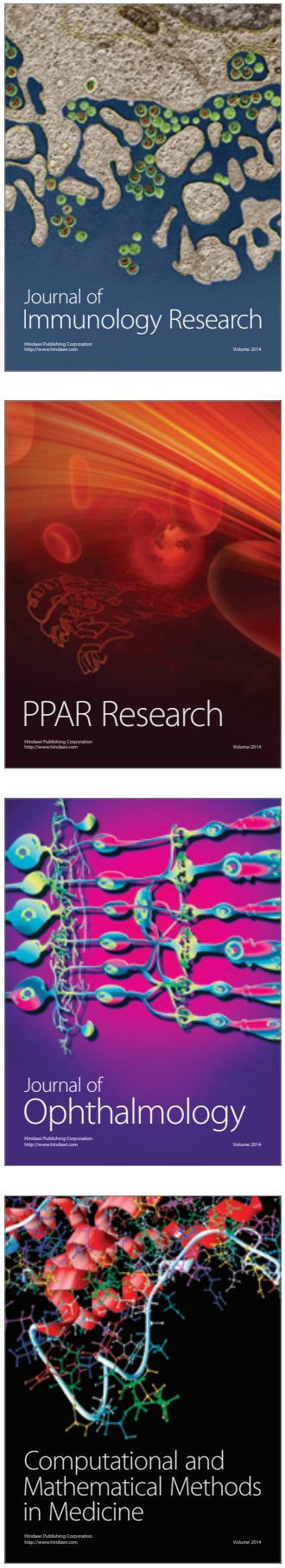

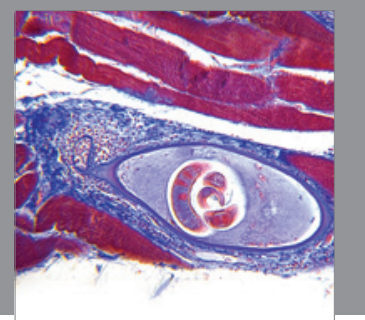

Gastroenterology

Research and Practice
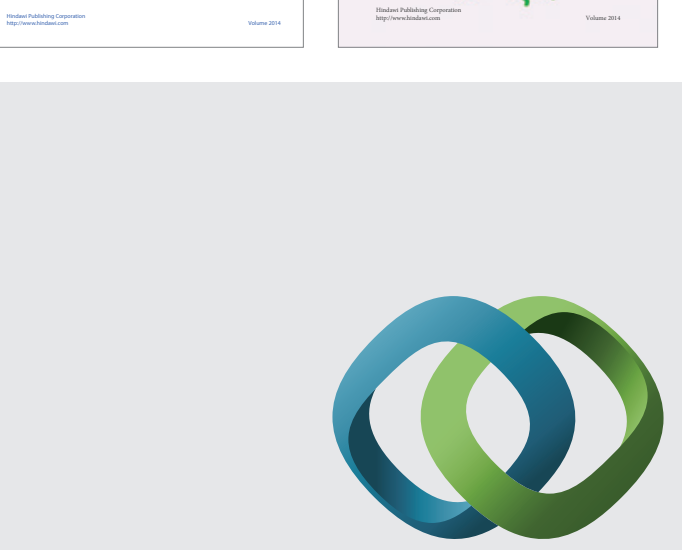

\section{Hindawi}

Submit your manuscripts at

http://www.hindawi.com
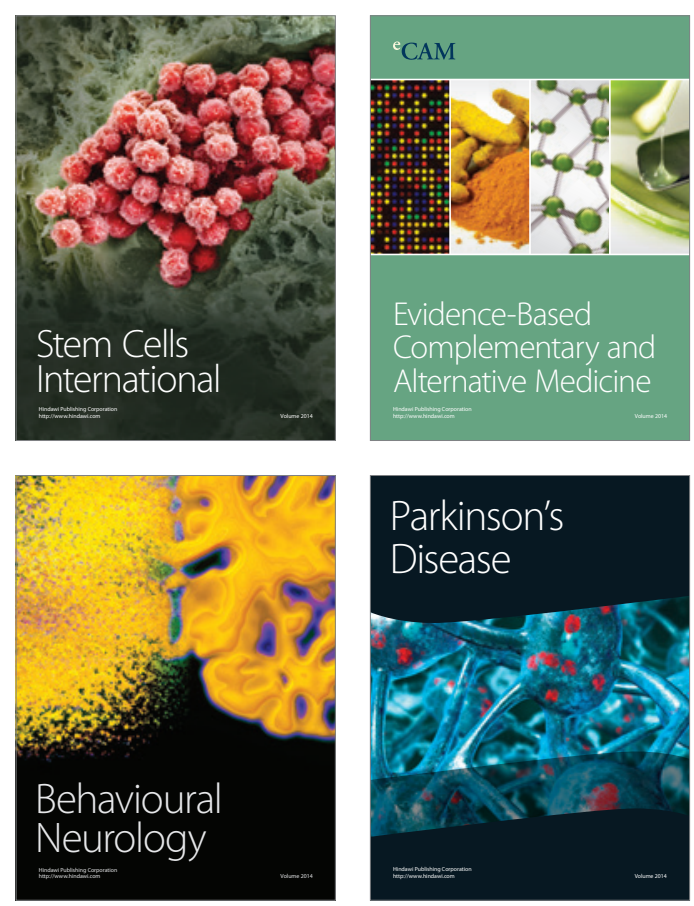

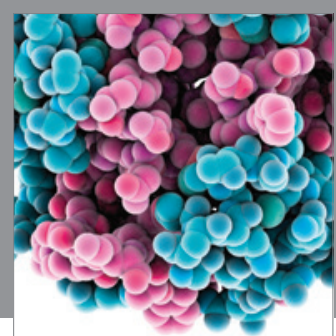

Journal of
Diabetes Research

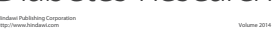

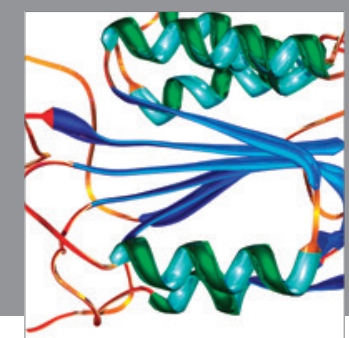

Disease Markers
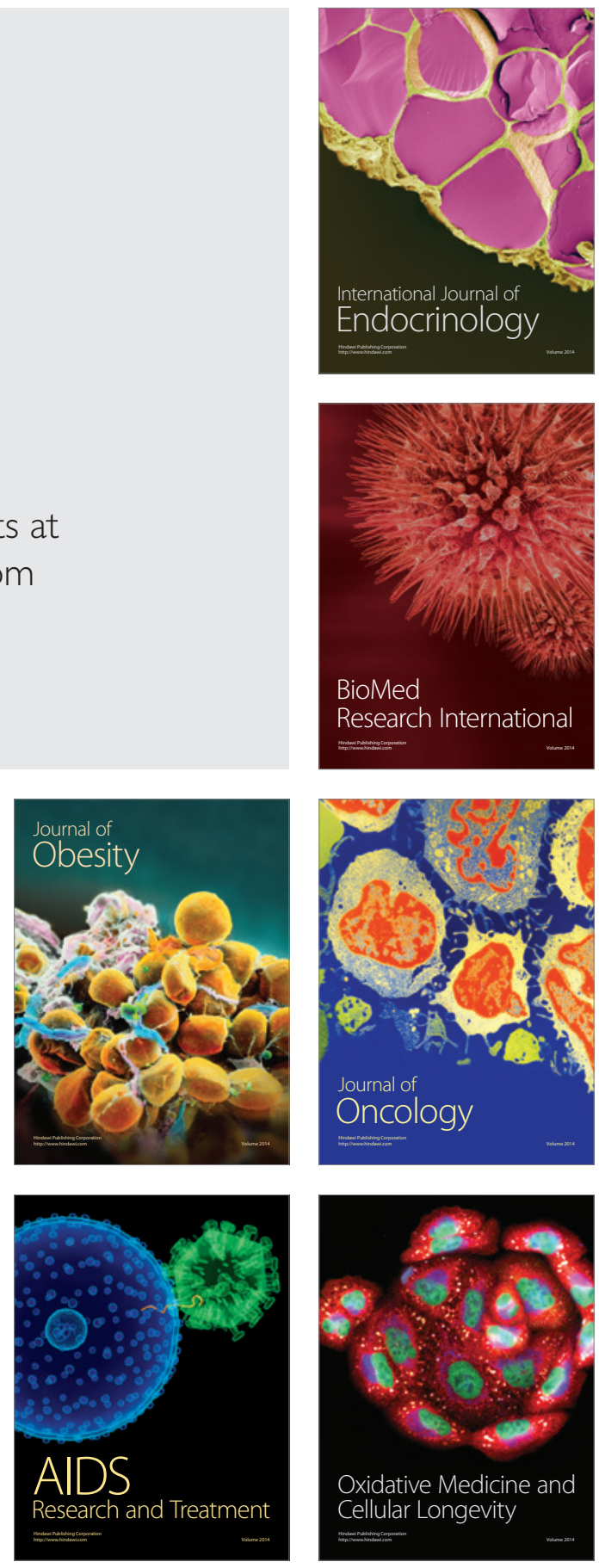